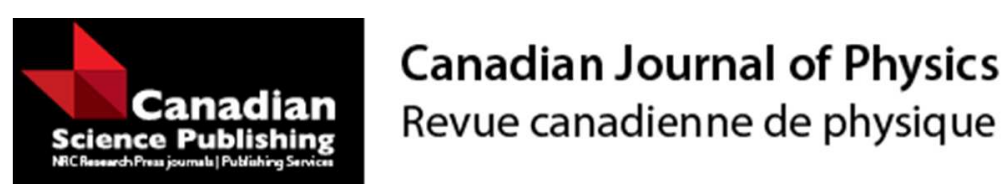

\title{
Investigations of gamma ray and fast neutron shielding properties of tellurite glasses with different oxide compositions
}

\begin{tabular}{|r|l|}
\hline Journal: & Canadian Journal of Physics \\
\hline Manuscript ID & cjp-2016-0330.R2 \\
\hline Manuscript Type: & Article \\
\hline Date Submitted by the Author: & 03-Aug-2016 \\
\hline Complete List of Authors: & Sayyed, M.I.; University of Tabouk \\
\hline Keyword: & $\begin{array}{l}\text { tellurite glasses, Y-ray, mass attenuation coefficient, effective atomic } \\
\text { number, radiation shielding }\end{array}$ \\
\hline \multicolumn{2}{|l}{} \\
\hline
\end{tabular}

\section{SCHOLARONE $^{\text {tw }}$ \\ Manuscripts}




\title{
Investigations of gamma ray and fast neutron shielding properties of tellurite glasses with different oxide compositions
}

\author{
M. I. Sayyed ${ }^{*}$ \\ Department of Physics, Faculty of Science, University of Tabuk, Tabuk, KSA
}

\begin{abstract}
In the present paper, the basic radiation parameters of tellurite glasses with different forming oxides $\left(\mathrm{B}_{2} \mathrm{O}_{3}, \mathrm{BaO}, \mathrm{K}_{2} \mathrm{O}, \mathrm{V}_{2} \mathrm{O}_{5}, \mathrm{WO}_{3}\right.$ and $\left.\mathrm{ZnO}\right)$ have been studied over a wide photon energy range from $1 \mathrm{keV}$ to $100 \mathrm{GeV}$, using WinXCom program. These parameters are the mass attenuation coefficient $(\mu / \rho)$, effective atomic number $\left(Z_{\text {eff }}\right)$ and electron density $\left(\mathrm{N}_{\mathrm{e}, \mathrm{eff}}\right)$. In addition, the macroscopic effective removal cross-sections $\left(\sum_{R}\right)$ for fast neutron have been calculated. The dependence of different parameters on incident photon energy and chemical content has been discussed. Among the selected glass systems $\mathrm{TeO}_{2}-\mathrm{WO}_{3}$ and $\mathrm{TeO}_{2}-\mathrm{B}_{2} \mathrm{O}_{3}$ showed superior shielding properties for $\gamma$-ray and neutron, respectively. It had been shown that the selected glass systems have higher values of the mass attenuation coefficients $(\mu / \rho)$ than concretes and $0.7 \mathrm{SiO}_{2}: 0.3 \mathrm{BaO}$ glass. These results indicate that tellurite glasses can be used as radiation shielding materials.
\end{abstract}

Keywords: tellurite glasses; $\gamma$-ray; mass attenuation coefficient; effective atomic number; radiation shielding.

\footnotetext{
* Corresponding author: M.I. Sayyed, mabualssayed@ut.edu.sa
} 


\section{Introduction}

Nowadays, nuclear radiation is increasingly being used in various fields such as medical, agriculture and scientific research and other scientific and technological fields. So it is important to evaluate shielding properties in different materials of technological importance. It is useful to develop the mixture of materials that can be used as a shield against nuclear radiation [1]. In such manner, glasses are promising materials because they can be transparent to visible light, simplicity to manufacture and its radiation shielding properties can be improved by the addition of oxide in the glass formula $[2,3]$.

Among several glass systems, tellurite glasses are of great interest because of their superior physical properties such as high refractive index [4], low melting temperature [5], high dielectric constant [6], good chemical resistance [7], high thermal stability [8] and low phonon energy [9-15].

Conventionally, lead-based glasses have been widely used for $\gamma$-ray radiation shielding and protection from other ionizing human harmful radiation because of its rich physical and chemical properties. But, due to their toxicant nature, they have been greatly restricted in various radiations shielding application. Nowadays, there have been increasing interests in preparation lead-free glasses suitable for radiation shielding [8, $16]$.

Different types of glasses could be used as radiation shielding material for gamma rays and neutrons [17-22]. Kirdsiri et al. [3] studied gamma-rays shielding and optical properties of lead borate glasses and silicate glass containing $\mathrm{Bi}_{2} \mathrm{O}_{3}, \mathrm{PbO}$ and $\mathrm{BaO}$ at 662 $\mathrm{keV}$. As reported by authors, as the additive oxide concentration increased, so did the photoelectric absorption. However, the Compton scattering decreased. Kaewkhao and Limsuwan [18] evaluated the mass attenuation coefficients and the values of effective atomic number for phosphate glass containing $\mathrm{Bi}_{2} \mathrm{O}_{3}, \mathrm{PbO}$ and $\mathrm{BaO}$ at $662 \mathrm{keV}$. The authors found that glasses containing heavy-metal oxide (HMO) like $\mathrm{Bi}_{2} \mathrm{O}_{3}$ are promising gamma-ray shielding materials due to their high effective atomic numbers and strong absorption of gamma rays. In addition, Chanthima et al [19] concluded that silicate 
glasses containing $\mathrm{Bi}_{2} \mathrm{O}_{3}, \mathrm{BaO}$ and $\mathrm{PbO}$ can be used as radiation shielding materials. They have calculated the mass attenuation coefficient $(\mu / \rho)$, effective atomic number $\left(\mathrm{Z}_{\text {eff }}\right)$, effective electron density $\left(\mathrm{N}_{\text {eff }}\right)$ and half-value layer (HVL), in the energy range 1 $\mathrm{keV}$ - $100 \mathrm{GeV}$. Kaur and Singh [23] calculated the mass attenuation coefficient, half value layer and mean free path values for lead borate glasses doped with aluminum oxide. The obtained results are in good agreement with standard nuclear radiation shielding concretes. Kurudirek et al [24] evaluated the effective atomic numbers $\left(Z_{\mathrm{eff}}\right)$, mean free paths and total mass attenuation coefficients of some lead and non-lead based glass systems, in the energy range of $1 \mathrm{keV}-100 \mathrm{GeV}$. The results were compared with some standard shielding concretes and commercial window glasses. Furthermore, Y1lmaz et al [25] evaluated the effective fast neutron removal cross-sections $\left(\sum_{\mathrm{R}}\right)$ for different concrete samples with and without mineral additives using NXcom program. They concluded that the elemental composition, hydrogen content and the concrete density contribute an important rule for neutrons attenuation.

In this work the mass attenuation coefficient $(\mu / \rho)$, the effective atomic number $\left(Z_{\text {eff }}\right)$, and the electron density $\left(\mathrm{N}_{\mathrm{e}, \text { eff }}\right)$ have been calculated for $\mathrm{TeO}_{2}-\mathrm{B}_{2} \mathrm{O}_{3}, \mathrm{TeO}_{2}-\mathrm{BaO}, \mathrm{TeO}_{2}-$ $\mathrm{K}_{2} \mathrm{O}, \mathrm{TeO}_{2}-\mathrm{V}_{2} \mathrm{O}_{5}, \mathrm{TeO}_{2}-\mathrm{WO}_{3}$ and $\mathrm{TeO}_{2}-\mathrm{ZnO}$ glasses. Furthermore, the macroscopic effective removal cross-section of fast neutrons was calculated in order to determine their effectiveness as gamma ray and neutron shielding material.

\section{Material and computational method}

The glass system in the present work is tellurite glasses with different glass oxides $\left(\mathrm{B}_{2} \mathrm{O}_{3}\right.$, $\mathrm{BaO}, \mathrm{K}_{2} \mathrm{O}, \mathrm{V}_{2} \mathrm{O}_{5}, \mathrm{WO}_{3}$ and $\mathrm{ZnO}$ ). The compositions and density of the glasses are listed in Table. 1

\subsection{Mass attenuation coefficient}

The mass attenuation coefficient is a measure of the probability of interactions of photon with matter and it is measured in $\left(\mathrm{cm}^{2} / \mathrm{g}\right)$ [26]. It is the basic tool used to derive other photon interaction parameters like effective atomic number and electron density. The 
values of mass attenuation coefficient can be calculated for chemical compounds or homogeneous mixtures using the following equation: [27].

$$
\mu / \rho=\sum_{\mathrm{i}} \mathrm{w}_{\mathrm{i}}(\mu / \rho)_{\mathrm{i}}
$$

where $\mathrm{w}_{\mathrm{i}}$ is the weight fraction of element $\mathrm{i}$ and $(\mu / \rho)_{\mathrm{i}}$ is the mass attenuation coefficient of the ith element . For the selected glass systems, the mass attenuation coefficients have been calculated by the WinXcom program [28]. This program is able to generate total cross sections, attenuation coefficients as well as partial cross sections for various interaction processes, such as incoherent and coherent scattering, photoelectric absorption and pair production, for elements, compounds and mixtures as needed at energies from 1 $\mathrm{keV}$ to $100 \mathrm{GeV}$.

\subsection{Effective atomic number $\left(Z_{\text {eff }}\right)$ and electron density $\left(N_{e, e f f}\right)$}

The effective atomic number $\left(Z_{\text {eff }}\right)$ is a parameter similar to the atomic number of elements. It describes the properties of the composite materials (compounds or mixtures) in terms of equivalent elements, and it varies with energy [29]. The effective atomic numbers of the selected glass systems were calculated using the following expression [30]:

$$
Z_{e f f}=\frac{\sum_{i} f_{i} A_{i}\left(\frac{\mu}{\rho}\right)_{i}}{\sum_{j} f_{j} \frac{A_{j}}{Z_{j}}\left(\frac{\mu}{\rho}\right)_{j}}
$$

here $f_{i}$ represents the fractional abundance of the element $i$ relative to the number of atoms providing that $\Sigma \mathrm{f}_{\mathrm{i}}=1, \mathrm{~A}_{\mathrm{i}}$ is the atomic weight, and $\mathrm{Z}_{\mathrm{i}}$ is the atomic number.

The effective atomic number is related to another parameter called effective electron density $\left(\mathrm{N}_{\mathrm{e}, \mathrm{eff}}\right)$ which is defined as the number of electrons per unit mass of the interacting materials and measured in electrons/g, which is calculated using the following equation [31]:

$$
N_{e, e f f}=N_{A} \frac{n Z_{e f f}}{\sum_{i} n_{i} A_{i}}=N_{A} \frac{Z_{e f f}}{\langle A\rangle}
$$

where $\langle A\rangle$ is the mean atomic mass and $\mathrm{N}_{\mathrm{A}}$ is Avogadro constant. 


\subsection{Macroscopic effective removal cross section for fast neutrons $\left(\sum_{R}\right)$}

The macroscopic effective removal cross-sections for fast neutrons $\sum_{R}$, or for simplicity the removal cross-section is the probability of one neutron undergoing a specific reaction per unit path length of travel through the shielding material [24]. For compounds and homogeneous mixtures, the values of the macroscopic removal cross-section $\left(\sum_{\mathrm{R}}\right)$ can be calculated for various elements in the compounds or mixtures using the following equation[32, 33]:

$$
\Sigma_{R}=\sum_{i} W_{i}\left(\sum_{R} / \rho\right)_{i}
$$

where $\mathrm{W}_{\mathrm{i}}$ is the partial density $\left(\mathrm{g} / \mathrm{cm}^{3}\right)$ and $\sum_{\mathrm{R} / \mathrm{p}}\left(\mathrm{cm}^{2} / \mathrm{g}\right)$ is the mass removal cross-section of the $i$ th constituent. The partial density $\mathrm{W}_{\mathrm{i}}$ of the ith constituent (compound or simple element) can be calculated using:

$$
W_{i}=w_{i} \rho_{s}
$$

where $\mathrm{w}_{\mathrm{i}}$ is the weight fraction of the $i$ constituent and $\rho_{\mathrm{s}}$ is the density of the sample. The $\Sigma_{R / p}$ is nearly constant for neutron energy from 2 to $12 \mathrm{MeV}$ [32]. The values obtained by Eq. (4) are accurate to within about $10 \%$ of those values which determined experimentally [34].

Theoretical and experimental values of the removal cross-sections $\left(\Sigma_{\mathrm{R} / \rho}\right)$ for elements and compounds have been tabulated $[32,35,36]$. Using these tables we can get the value of the removal cross section $\sum_{\mathrm{R}}$ for any compound or material not listed in these tables by using the last equations.

\section{Results and discussion}

In this work, the basic gamma and neutron shielding parameters of $\mathrm{TeO}_{2}$ based glasses were studied using WinXcom [28] program over wide photon energy range from $1 \mathrm{KeV}$ to $1 \mathrm{GeV}$. These parameters are the mass attenuation coefficient $(\mu / \rho)$, the effective atomic number $\left(\mathrm{Z}_{\mathrm{eff}}\right)$ and the effective electron density $\left(\mathrm{N}_{\mathrm{e}}\right.$, eff). Furthermore, the macroscopic effective removal cross-sections $\left(\sum_{R}\right)$ for fast neutron were calculated. 
The variations of the mass attenuation coefficient, within photon energy, of the selected glass systems, are shown in Fig. 1 a-b. The variations of the effective atomic numbers and the electron densities, of the selected glasses, for different photon interactions at varying photon energies are shown in Fig. 2 and Fig. 3 respectively. The obtained results of tellurite glasses have been compared in terms of $(\mu / \rho)$ values with some standard radiation shielding concretes and silicate glasses (Figs. 4-5). In addition, the values of $\sum_{R}$ are listed in Table 3.

\subsection{Mass attenuation coefficients $(\mu / \rho)$}

Fig.1-a shows that the values of $\mu / \rho$, for the investigated tellurite glass systems, are very large in the low energy region $(\mathrm{E}<500 \mathrm{keV})$ and are gradually reduced with increment of the energy. In the intermediate energy region $(500 \mathrm{KeV}<\mathrm{E}<5 \mathrm{MeV})$, it is clear that $\mu / \rho$ values decrease at a slower rate, whereas for $\mathrm{E}>6 \mathrm{MeV}, \mu / \rho$ values increase slowly up to $800 \mathrm{MeV}$ and become almost constant thereafter. (Fig. $1 \mathrm{~b}$ ). Fig.1-a shows also some discontinuities of $\mu / \rho$ values. The energy of these discontinuities corresponds to photoelectric absorption edges of the high Z-elements, $\mathrm{K}, \mathrm{V}, \mathrm{Zn}, \mathrm{Te}, \mathrm{Ba}$ and $\mathrm{W}$ as shown in Table 2. The absorption edges of the low- $\mathrm{Z}$ elements $\mathrm{B}$ and $\mathrm{O}$ occur at energies less than $1 \mathrm{keV}$ hence there are of no importance in this work. Also, from Fig. $1 \mathrm{a}-\mathrm{b}$ it is observed that $\mathrm{TeO}_{2}-\mathrm{WO}_{3}$ glass has the largest $\mu / \rho$ value. Hence, $\mathrm{TeO}_{2}-\mathrm{WO}_{3}$ glass is a superior gamma ray shielding.

\subsection{Effective atomic numbers $\left(Z_{e f f}\right)$ and electron densities $\left(N_{e, e f f}\right)$}

The $\mathrm{Z}_{\text {eff }}$ values of tellurite glass systems in this work were determined by using the values of $(\mu / \rho)$. The atomic numbers and atomic masses of the elements were taken from IUPAC [37]. The variation of $Z_{\text {eff }}$ values, versus incident photon energy, are shown in Figs. 2.

These variations, which can be classified to three energy region, are attributed to the dominance of different photon interactions. These observed variations can be easily explained by adopting the three well-known photon scattering in matter. The photoelectric effect appears in the lower energy regions, while the pair production 
processes and Compton scattering process appear in the higher and intermediate energy regions, respectively.

Due to the dominance of photoelectric interaction process at lower energies, the higher values of $Z_{\text {eff }}$ have been observed in this region. However, various jumps of $Z_{\text {eff }}$ values were found in this region, for all selected glass systems, due to the photoelectric absorption edges of K, L and M (see Table 2).

With further increase in incident photon energy from $0.1 \mathrm{MeV}$ to $10 \mathrm{MeV}$, the $Z_{\text {eff }}$ values become almost independent of incident photon energy which may be due to dominance of Compton scattering process. In Compton scattering region, the interaction cross section is directly proportional to atomic number $Z$, hence the minimum value of $Z_{\text {eff }}$ for the selected glass systems was observed in this region.

Finally, in high energy region (beyond $10 \mathrm{MeV}$ ), the $\mathrm{Z}_{\text {eff }}$ value increases with photon energy and becomes almost constant above $100 \mathrm{MeV}$. This can be attributed to the dominance of pair production in this energy region.

In addition, among the selected glass systems, $\mathrm{TeO}_{2}-\mathrm{WO}_{3}$ shows maximum value for the effective atomic numbers. It may be due to the reason that $\mathrm{TeO}_{2}-\mathrm{WO}_{3}$ contains tungsten which is an element with relatively high atomic number $(Z=74)$. It can be concluded that $\mathrm{TeO}_{2}-\mathrm{WO}_{3}$ is the most effective for shielding gamma rays.

The dependency of the electron density $\left(\mathrm{N}_{\mathrm{e}, \text { eff }}\right)$ of the selected glass systems on photon energy is shown in Fig. 3. As seen from this Figure, the variation of $\mathrm{N}_{\mathrm{e}, \text { eff }}$ was similar to that observed for $Z_{\text {eff. }}$.

\subsection{Comparison with standard gamma ray shielding concretes and silicate glasses}

The obtained results of tellurite glass systems have been compared in terms of $\mu / \rho$ values with different standard radiation shielding concretes [38], $0.7 \quad \mathrm{SiO}_{2}: 0.3 \mathrm{Bi}_{2} \mathrm{O}_{3}, 0.7$ $\mathrm{SiO}_{2}: 0.3 \mathrm{PbO}$ and $0.7 \mathrm{SiO}_{2}: 0.3 \mathrm{BaO}$ glasses [19]. The results are shown graphically in Fig[4] and Fig.[5] respectively. From these figures, it can be observed that all the investigated glass systems exhibited with slightly higher values of mass attenuation 
coefficient against standard radiation shielding concretes and $0.7 \mathrm{SiO}_{2}: 0.3 \mathrm{BaO}$ glass. The exceptionis seen in the intermediate energy region where the total mass attenuation coefficient seems to be independent of chemical composition. These results indicated that the investigated glasses can be used as radiation shielding materials.

\subsection{Effective removal cross section of fast neutrons}

The results of the calculated effective removal cross-sections for fast neutron, $\Sigma_{R}$ of the selected glasses are tabulated in Table 3. From this table it can be seen that the values of $\sum_{\mathrm{R}}$ of different tellurite glasses are very close and ranged from $0.0924 \mathrm{~cm}^{-1}$ for $\mathrm{TeO}_{2}-\mathrm{K}_{2} \mathrm{O}$ $\left(\rho=4.50 \mathrm{~g} / \mathrm{cm}^{3}\right)$ to $0.1204 \mathrm{~cm}^{-1}$ for $\mathrm{TeO}_{2}-\mathrm{B}_{2} \mathrm{O}_{3}\left(\rho=4.97 \mathrm{~g} / \mathrm{cm}^{3}\right)$. The higher value of $\sum_{\mathrm{R}}$ for $\mathrm{TeO}_{2}-\mathrm{B}_{2} \mathrm{O}_{3}$ may be attributed to boron which is light element with high mass removal cross-section (compared to $\mathrm{Ba}, \mathrm{K}, \mathrm{V}, \mathrm{W}$ and $\mathrm{Zn}$ ). Also, it was found that $\mathrm{TeO}_{2}-\mathrm{WO}_{3}$ which posses a high density has a high value of removal cross section, while minimum $\sum_{\mathrm{R}}$ are observed for $\mathrm{TeO}_{2}-\mathrm{K}_{2} \mathrm{O}$ (lowest density). Then it is concluded that the density of the sample is an important parameter affecting neutron attenuation. Furthermore, it was found that the $\Sigma_{R}$ values of the selected glasses were larger than silicate and borate heavy metal oxide glasses [16]. Finally, since $\mathrm{TeO}_{2}-\mathrm{B}_{2} \mathrm{O}_{3}$ has the largest value of $\Sigma_{\mathrm{R}}$, hence it is the most suitable for neutron shielding.

\section{Conclusions}

Shielding properties of tellurite glasses with different glass oxides were investigated. We have determined the mass attenuation coefficient $(\mu / \rho)$, the effective atomic number $\left(\mathrm{Z}_{\mathrm{eff}}\right)$ and the electron density $\left(\mathrm{N}_{\mathrm{e}, \text { eff }}\right)$ for total photon interaction, in the energy range of 1 $\mathrm{keV}$ to $100 \mathrm{GeV}$. Furthermore, the macroscopic effective removal cross section for fast neutrons $\left(\sum_{\mathrm{R}}\right)$ has been calculated. From the present study the following conclusions can be made:

- The values of $\mu / \rho, Z_{\text {eff }}$ and $\mathrm{N}_{\mathrm{e}}$ depend on the incident photon energy. 
- Among the selected tellurite glasses, $\mathrm{TeO}_{2}-\mathrm{WO}_{3}$ appears as best gamma ray shielding glass due to higher values for mass attenuation coefficient and effective atomic number.

- The highest macroscopic effective removal cross-section value was recorded for $\mathrm{TeO}_{2}-\mathrm{B}_{2} \mathrm{O}_{3}$ so it's good material for neutrons shielding applications, while the lowest value was recorded for $\mathrm{TeO}_{2}-\mathrm{K}_{2} \mathrm{O}$.

- The obtained results of tellurite glasses have been compared, in terms of mass attenuation coefficient values, with some standard shielding concretes (ordinary, hematite-serpentine, ilmenite and steel-scrap). It was found that tellurite glasses have higher values of $(\mu / \rho)$ than concretes.

All the obtained results indicated that tellurite glasses are promising materials for gamma rays shielding applications.

\section{Acknowledgment}

The financial support from University of Tabuk is gratefully acknowledged.

\section{References}

[1] J. F. Krocher and R. E. Browman, E_ects of radiation on materials and components (Reinhold, New York, 1984).

[2] J. Kaewkhao, K. Kirdsiri, P. Limkitjaroenporn, P. Limsuwan, Jeongmin Park, H. J. Kim, J. Kor Phys. Soc. 59 (2011) 661.

[3] K. Kirdsiri, J. Kaewkhao, N. Chanthima, P. Limsuwan, Ann. Nuc. Ene. 38 (2011) 1438.

[4] D. Munoz-Martin, M.A. Villegas, J. Gonzalo, J.M. Fernandez-Navarro, J. Eur. Ceram.Soc. 29 (2009) 2903.

[5] J.E. Stanworth, J. Soc. Glas. Technol. 36 (1952) 217. 
[6] M.M. Ahmad, E.S. Yousef, E.S. Moustafa, Physica B 371 (2006) 74.

[7] I. Shaltout, Y. Tang, R. Braunstein, E.E. Shaisha, J. Phys. Chem. Solids 57 (1996) 1223.

[8] H. Fares, I. Jlassi, H. Elhouichet, M. Férid, J. Non-Cryst. Solids (2014) 396-397, 1.

[9] M. Çelikbilek, A.E. Ersundu, S. Aydin, J. Non-Cry. Solids 378 (2013) 247.

[10] S. Azianty, A.K. Yahya.. J. Non-Cry. Solids 378 (2013) 234.

[11] H. Fares, H. Elhouichet, B. Gelloz, and M. Férid, J. Appl. Phys. 116 (2014) 123504.

[12] M. Çelikbilek, A.E. Ersundu, N. Solak, S. Aydin, , J. Non-Cryst. Solids, 357 (2011) 88.

[13] W. Stambouli, H. Elhouichet, M. Ferid, J. Mol. Struc. 1028 (2012) 39.

[14] M. Çelikbilek, A.E. Ersundu, E.O. Zayim, S. Aydin, J. Alloys comp., 637 (2015) 162.

[15] J.C.S. Moraes , J.A. Nardi , S.M. Sidel , B.G. Mantovani , K. Yukimitu , V.C.S. Reynoso a, L.F. Malmonge , N. Ghofraniha , G. Ruocco , L.H.C. Andrade , S.M. Lima, J. Non-Cryst. Solids 356 (2010) 2146.

[16] Singh VR, Badiger NM and Kaewkhao, 2014 . J Non-Cryst. Solids 404 167-173.

[17] Kaewkhao, J., Pokaipisit, A., Limsuwan, P., 2010 . J. Nucl. Mater. 399, 38-40.

[18] Kaewkhao, J., Limsuwan, P., 2010. Nucl. Instrum. Methods A 619, 295-297

[19] N. Chanthima, J. Kaewkhao, P. Limsuwan, Annals of Nuclear Energy 41 (2012) 119-124

[20] N. Chanthima, J. Kaewkhao, Annals of Nuclear Energy 55 (2013) 23-28 
[21] P. Yasaka, N. Pattanaboonmee, H.J. Kim, P. Limkitjaroenporn, J. Kaewkhao, Annals of Nuclear energy, 2014, Vol. 68, pp. 4-9.

[22] S. Ruengsri, S. Insiripong, N. Sangwaranatee, J. Kaewkhao, Progress in Nuclear Energy 83 (2015) 99-104.

[23] S. Kaur, K. J. Singh, Ann. Nuc. Energy 63 (2014) 350.

[24] M. Kurudirek, Y. Özdemir , Ö. Simsek , R. Durak, J. Nuc. Materials 407 (2010) 110.

[25] E. Yılmaz, H. Baltas, E. Kırıs, I. Ustabas, U. Cevik , A. M. El-Khayatt, Ann. Nucl. Energy 38 (2011) 2204.

[26] J. H. Hubbell, Review of photon interaction cross section data in the medical and biological context. Phys. Med. Biol. 44 (1999), R1.

[27] M.I.Sayyed, J. Alloys and compounds 688 (2016) 111.

[28] L. Gerward, N. Guilbert, K. B. Jensen, H. Levring, Radiat.Phys.Chem.71 (2004) 653.

[29] F. Akman, R. Durak, M. F. Turhan, M. R. Kaçal, App. Rad. Isot. 101(2015) 107.

[30] M.I.Sayyed, Chin. J.Phys. 54 (2016) 408.

[31] E. Kavaz, U. Perişanoğlu, N. Ekinci , Y. Özdemir , Int J Radiat Biol. 2016 28,1-8.

[32] M. F. Kaplan, Concrete radiation shielding, Wiley, New York 1989. 
[33] J. Wood, Computational Methods in Reactor Shielding. Pergamon Press, New York 1982.

[34]S. Glasstone, A. Sesonske, Nuclear Reactor Engineering, third ed. CBS Publishers \& Distributors, Shahdara, Delhi, India 1986.

[35] A. B. Chilton, J. k. Shultis, R. E. Faw,. Principles of Radiation Shielding. PrenticeHall, Englewood Cliffs, NJ 1984.

[36] A. E. Profio, Radiation Shielding and Dosimetry. John Wiley \& Sons, Inc., New York 1979.

[37] E. W. Michael et al. Pure Appl. Chem.85 (2013)1047.

[38] I. I. Bashter, Ann. Nucl. Energy, 24 (1997) 1389. 
Table 1: Chemical compositions and density of the investigated tellurite glasses.

\begin{tabular}{lcc}
\hline \hline Glass description & Density $\left(\mathrm{g} / \mathrm{cm}^{3}\right)$ & Weight fraction in percentage \\
$80 \mathrm{TeO}_{2}-20 \mathrm{~B}_{2} \mathrm{O}_{3}$ & 4.97 & $\mathrm{Te}(0.640), \mathrm{O}(0.298), \mathrm{B}(0.062)$ \\
$80 \mathrm{TeO}_{2}-20 \mathrm{BaO}$ & 5.58 & $\mathrm{Te}(0.640), \mathrm{O}(0.181), \mathrm{Ba}(0.179)$ \\
$80 \mathrm{TeO}_{2}-20 \mathrm{~K}_{2} \mathrm{O}$ & 4.50 & $\mathrm{Te}(0.640), \mathrm{O}(0.194), \mathrm{K}(0.166)$ \\
$80 \mathrm{TeO}_{2}-20 \mathrm{~V}_{2} \mathrm{O}_{5}$ & 4.90 & $\mathrm{Te}(0.640), \mathrm{O}(0.248), \mathrm{V}(0.112)$ \\
$80 \mathrm{TeO}_{2}-\mathrm{WO}_{3}$ & 5.95 & $\mathrm{Te}(0.640), \mathrm{O}(0.202), \mathrm{W}(0.159)$ \\
$80 \mathrm{TeO}_{2}-20 \mathrm{ZnO}$ & 5.14 & $\mathrm{Te}(0.640), \mathrm{O}(0.200), \mathrm{Zn}(0.161)$ \\
\hline \hline
\end{tabular}


Table 2. Photon energies (in $\mathrm{KeV}$ ) of absorption edges for elements.

\begin{tabular}{lllllllllll}
\hline \hline Element & Z & M5 & M4 & M3 & M2 & M1 & L3 & L2 & L1 & K \\
\hline $\mathrm{K}$ & 19 & - & - & - & - & - & - & - & - & 3.607 \\
\hline $\mathrm{V}$ & 23 & - & - & - & - & - & - & - & - & 5.465 \\
\hline $\mathrm{Zn}$ & 30 & - & - & - & - & - & 1.020 & 1.043 & 1.194 & 9.659 \\
\hline $\mathrm{Te}$ & 52 & - & - & - & - & 1.006 & 4.340 & 4.612 & 4.939 & 31.180 \\
\hline $\mathrm{Ba}$ & 56 & - & - & 1.062 & 1.137 & 1.293 & 5.247 & 5.624 & 5.989 & 37.440 \\
\hline $\mathrm{W}$ & 74 & 1.809 & 1.872 & 2.281 & 2.575 & 2.820 & 10.210 & 11.540 & 12.100 & 69.530 \\
\hline \hline
\end{tabular}

Table 3 Calculations of effective removal cross sections $\sum_{\mathrm{R}}\left(\mathrm{cm}^{-1}\right)$ of the investigated tellurite glasses

Samples

\begin{tabular}{lllllll}
\hline & $\mathrm{TeO}_{2}-\mathrm{B}_{2} \mathrm{O}_{3}$ & $\mathrm{TeO}_{2}-\mathrm{BaO}$ & $\mathrm{TeO}_{2}-\mathrm{K}_{2} \mathrm{O}$ & $\mathrm{TeO}_{2}-\mathrm{V}_{2} \mathrm{O}_{5}$ & $\mathrm{TeO}_{2}-\mathrm{WO}_{3}$ & $\mathrm{TeO} 2-\mathrm{ZnO}$ \\
\hline$\sum_{\mathrm{R}}\left(\mathrm{cm}^{-1}\right)$ & 0.1204 & 0.1018 & 0.0924 & 0.1030 & 0.1100 & 0.1007 \\
\hline \hline
\end{tabular}




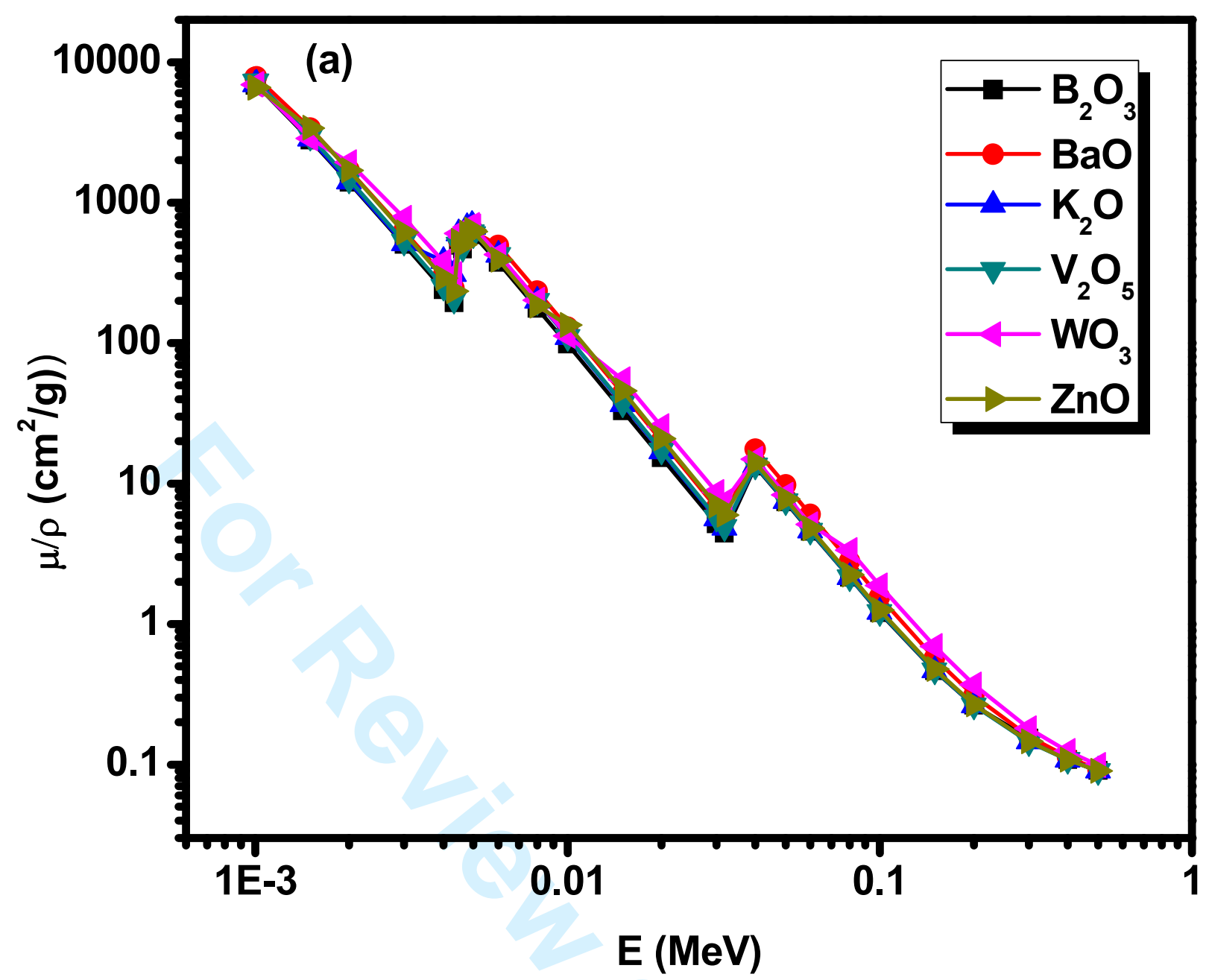

Fig.1.a Mass attenuation coefficients for the selected tellurite glasses in the low energy region $(\mathrm{E}<500 \mathrm{keV})$. 


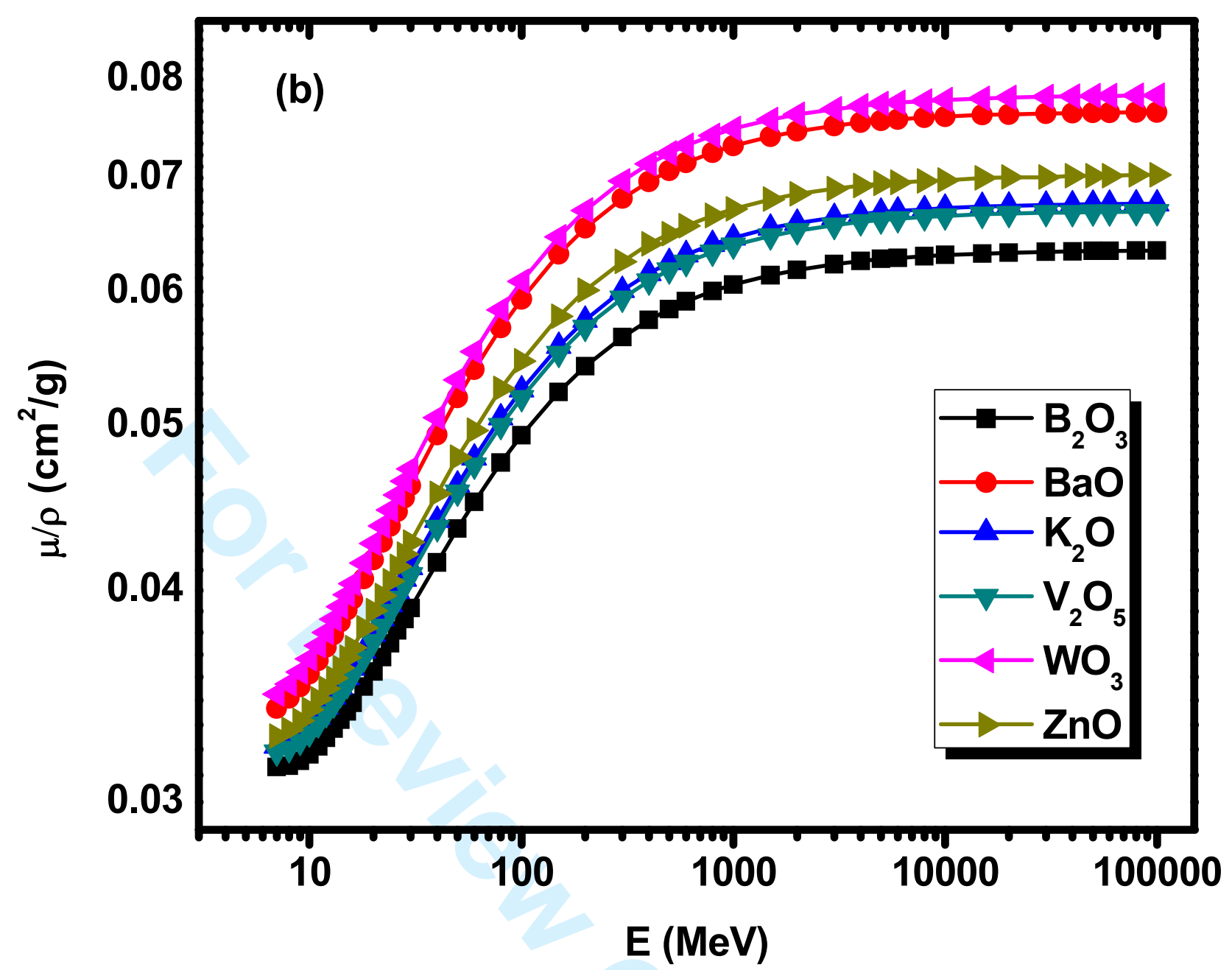

Fig1.b. Mass attenuation coefficients for the selected tellurite glasses in the energy region $(\mathrm{E}>500 \mathrm{keV})$. 


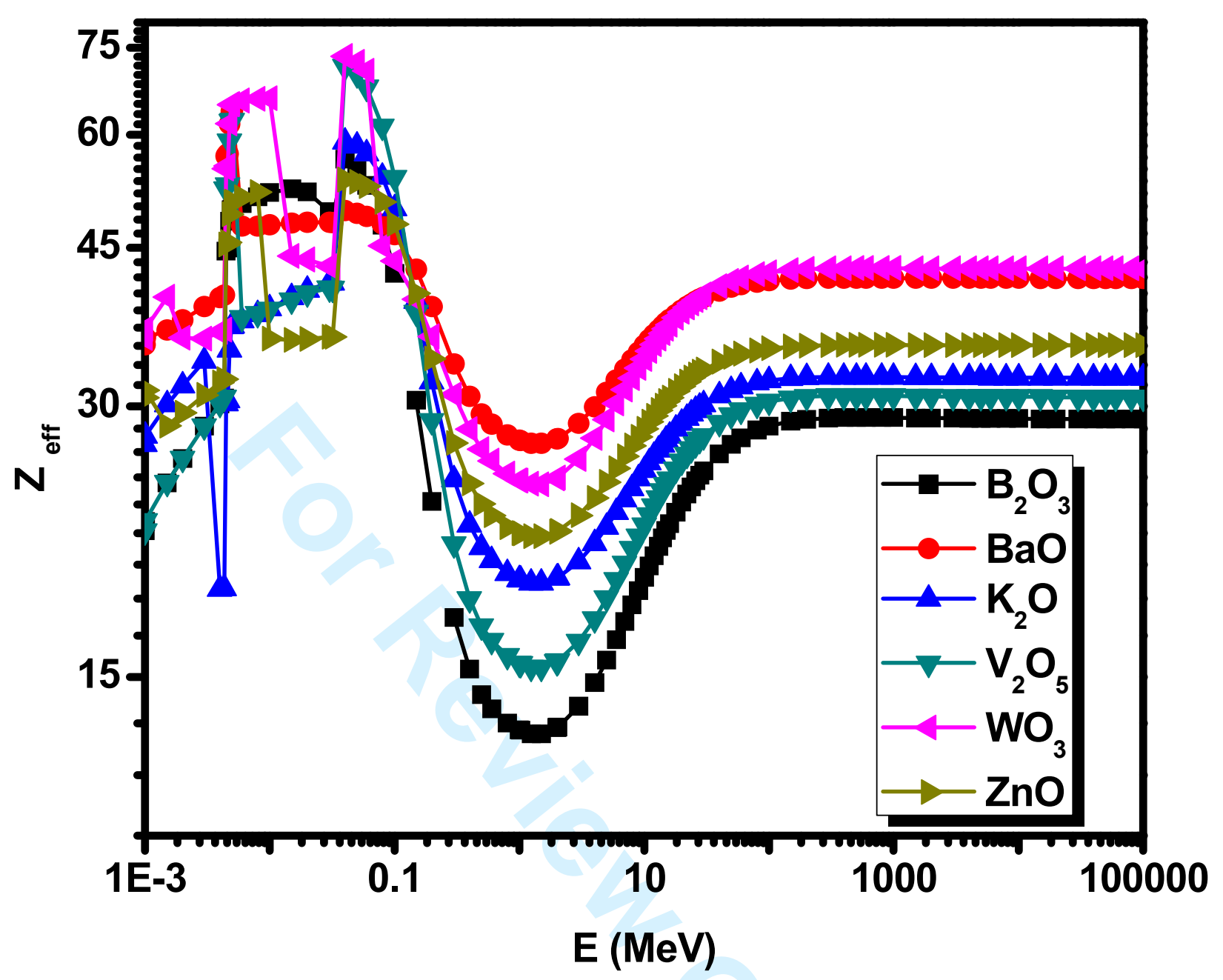

Fig. 2 Effective atomic number $\left(Z_{\text {eff }}\right)$ for the selected tellurite glasses with photon energy for total interaction from $1 \mathrm{KeV}$ to $100 \mathrm{GeV}$. 


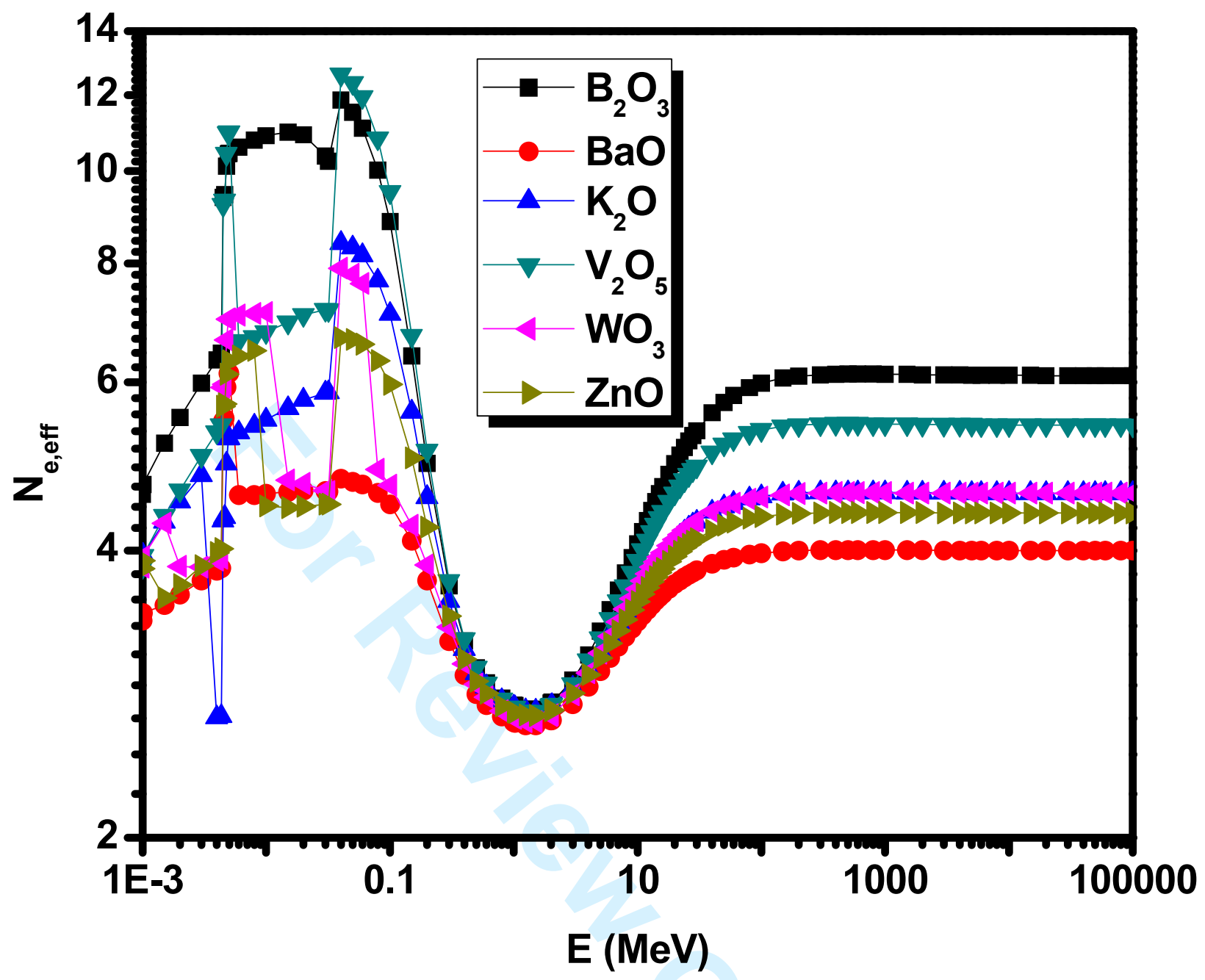

Fig.3 Electron density ( $\mathrm{N}_{\mathrm{e}, \text { eff }}$ for the selected tellurite glasses with photon energy for total interaction from $1 \mathrm{KeV}$ to $100 \mathrm{GeV}$. 


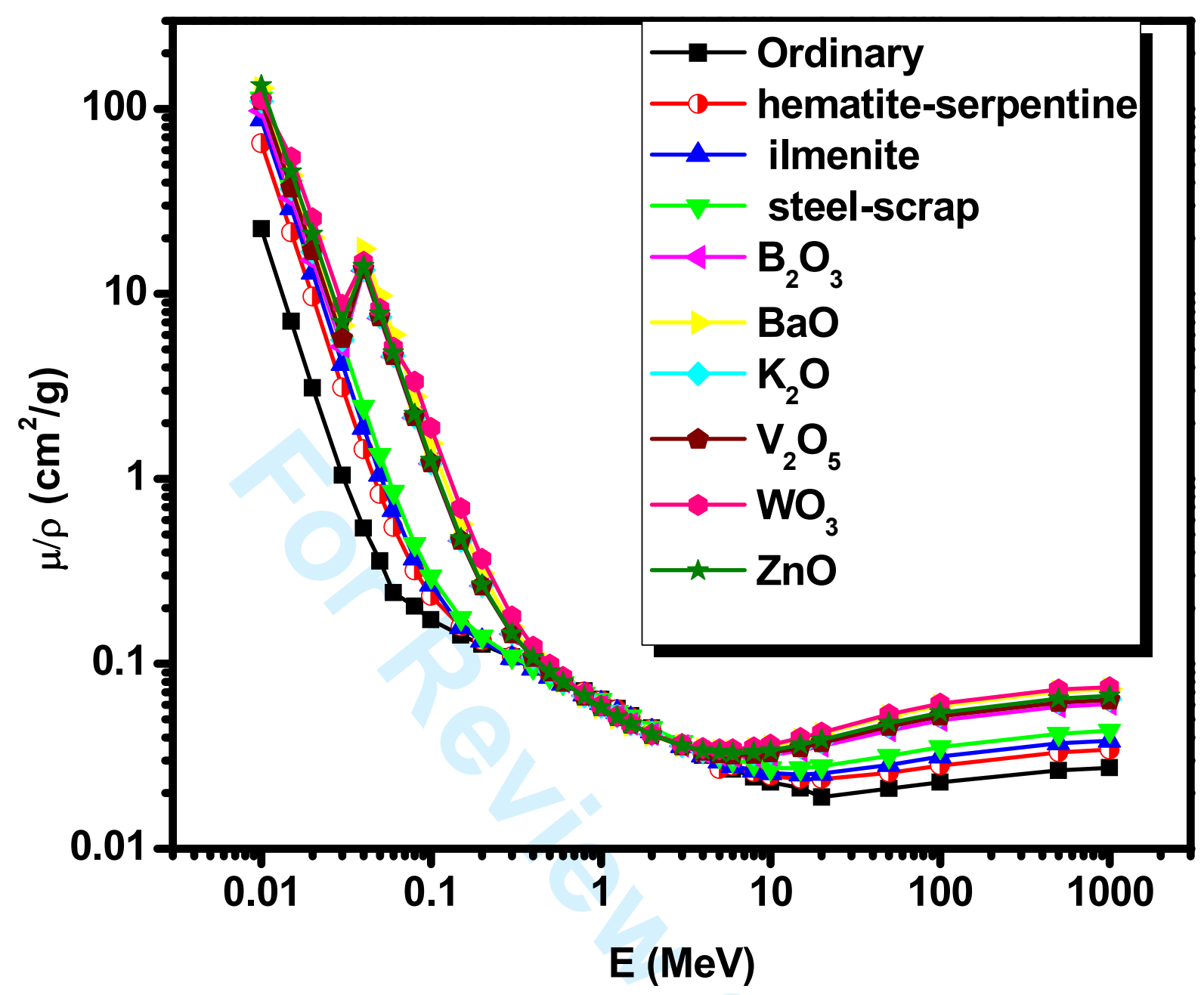

Fig. 4 Mass attenuation coefficients for the selected tellurite glasses in comparison to some standard shielding materials. 


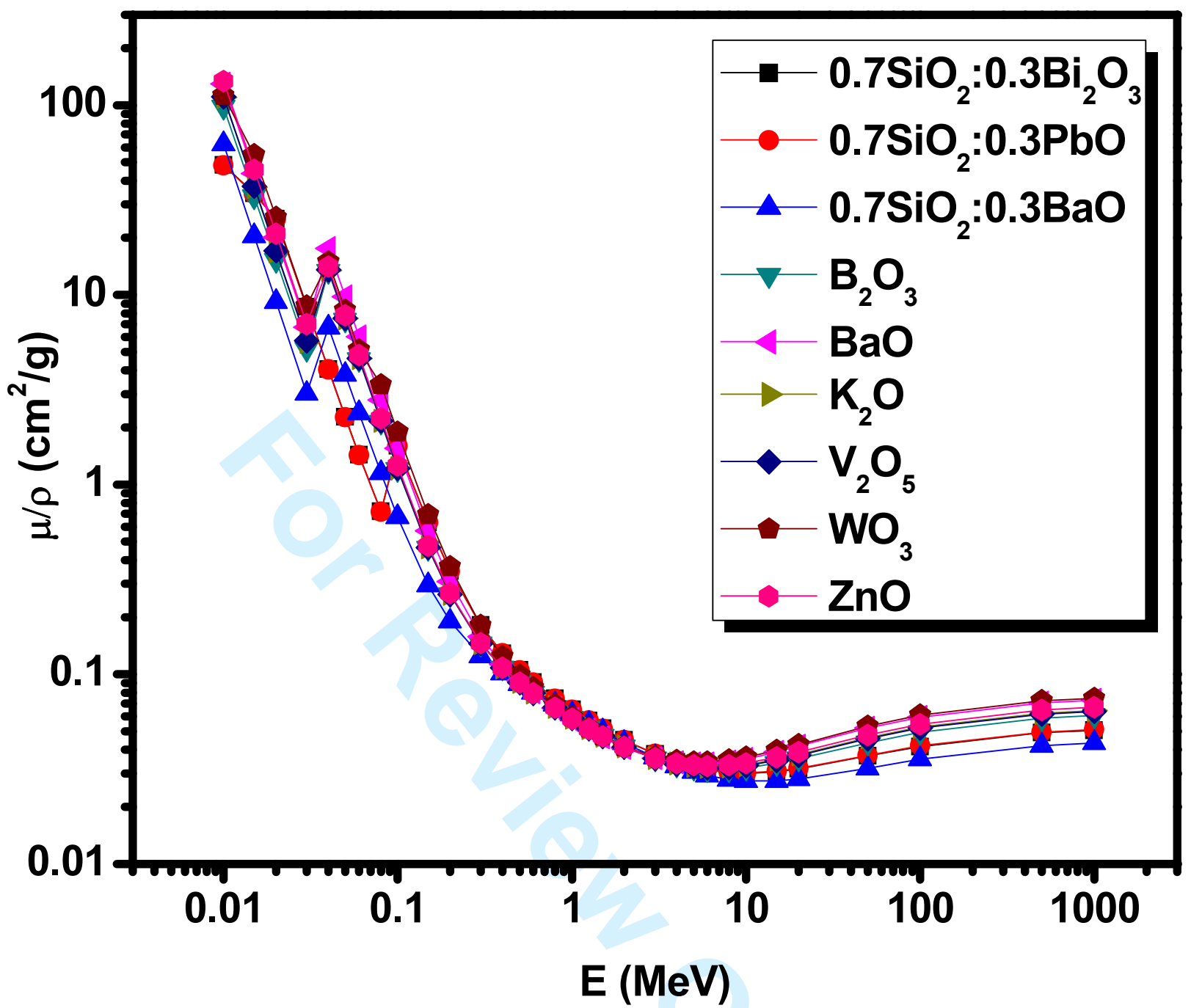

Fig.5 Mass attenuation coefficients for the selected tellurite glasses in comparison to $0.7 \mathrm{SiO}_{2}: 0.3 \mathrm{Bi}_{2} \mathrm{O}_{3}, 0.7 \mathrm{SiO}_{2}: 0.3 \mathrm{PbO}$ and $0.7 \mathrm{SiO}_{2}: 0.3 \mathrm{BaO}$. 